\title{
Role of the polymorphic region 1 of the Bordetella pertussis protein pertactin in immunity
}

\author{
Audrey J. King, ${ }^{1,4}$ Guy Berbers, ${ }^{2}$ Hans F. L. M. van Oirschot, ${ }^{1}$ \\ Peter Hoogerhout, ${ }^{3}$ Karen Knipping ${ }^{2}$ and Frits R. Mooi ${ }^{1,4}$
}

Author for correspondence: Frits R. Mooi. Tel: +31 30 2743091. Fax: +31 302744449.

e-mail:fr.mooi@rivm.nl

1,2,3 Research Laboratory for Infectious Diseases', Laboratory for Clinical Vaccine Research ${ }^{2}$ and Laboratory for Vaccine Research ${ }^{3}$, National Institute of Public Health and the Environment, PO Box 1, 3720 BA Bilthoven, The Netherlands

4 Eijkman Winkler Institute, University Medical Centre Utrecht, Heidelberglaan 100, 3584 CX, Utrecht, The Netherlands

\begin{abstract}
In several countries pertussis is re-emerging, despite a high vaccination coverage. It is suggested that antigenic divergence between Bordetella pertussis vaccine strains and circulating strains, in particular with respect to pertactin, has contributed to pertussis re-emergence. Polymorphism in pertactin is essentially limited to region 1, which is composed of repeats and is located adjacent to an Arg-Gly-Asp motif implicated in adherence. Evidence is provided for the immunological relevance of polymorphism in region 1. Region 1 was found to contain a B-cell epitope recognized in both humans and mice. Furthermore, variation in region 1 affected antibody binding and, in a mouse respiratory infection model, the efficacy of a whole-cell vaccine. Moreover, passive and active immunization indicated that region 1 confers protective immunity. An mAb directed against a linear conserved epitope conferred crossimmunity against isolates with distinct pertactin variants. The results indicate an important role of region 1 of pertactin in immunity.
\end{abstract}

Keywords: antigenic variation, P.69/pertactin, immunization, protective immunity

\section{INTRODUCTION}

Bordetella pertussis is the principal aetiological agent of whooping cough or pertussis, a respiratory disease that is most severe in infants and young children. In the prevaccination era, nearly every child contracted whooping cough and this infection was a major cause of infant death throughout the world (Willems \& Mooi, 1996). For about 40 years, widespread immunization of young children with whole-cell pertussis vaccines (WCVs) has been successful in controlling the disease. However, in recent years the incidence of pertussis has increased in a number of countries, including Australia, Canada, USA and The Netherlands, despite a high vaccination coverage (Andrews et al., 1997; Bass \& Stephenson, 1987; Bass \& Wittler, 1994; de Melker et al., 1997; DeSerres et al., 1995). We have previously reported that two B. pertussis antigens implicated in protective immunity, pertactin

\footnotetext{
Abbreviations: HRP, horseradish peroxidase; MBP, maltose-binding protein; WCV, whole-cell pertussis vaccine.

The GenBank accession numbers for the sequences reported in this paper are AJ011015, AJ011016, AJ011091, AJ011092, AJ011093, AJ132095, AJ245927 and X54547.
}

and pertussis toxin, are polymorphic (Mooi et al., 1998). Three protein variants of both pertactin and pertussis toxin were found in Dutch clinical isolates collected from 1949 to 1996. Temporal trends in the frequencies of pertactin and pertussis toxin variants indicated a divergence between vaccine strains and clinical isolates (Mooi et al., 1998, 1999).

A number of studies have shown that the B. pertussis fimbriae, filamentous haemagglutinin, pertussis toxin and pertactin can induce protection in both animals and humans (Sato \& Sato, 1984; Zhang et al., 1985; Kimura et al., 1990; Robinson et al., 1985; Shahin et al., 1990). Therefore, these proteins have been included in acellular pertussis vaccines. The importance of pertactin as a protective antigen is particularly convincing: the presence of antibodies against pertactin has been shown to correlate with clinical protection (Cherry et al., 1998; Storsaeter et al., 1998). Furthermore, acellular vaccines containing pertactin have been reported to give better protection than vaccines without this component (Hewlett, 1997; Plotkin \& Cadoz, 1997). Pertactin belongs to a family of secreted proteins designated autotransporter proteins (Henderson et al., 1998). It is produced as a large (910 aa) precursor molecule which is 


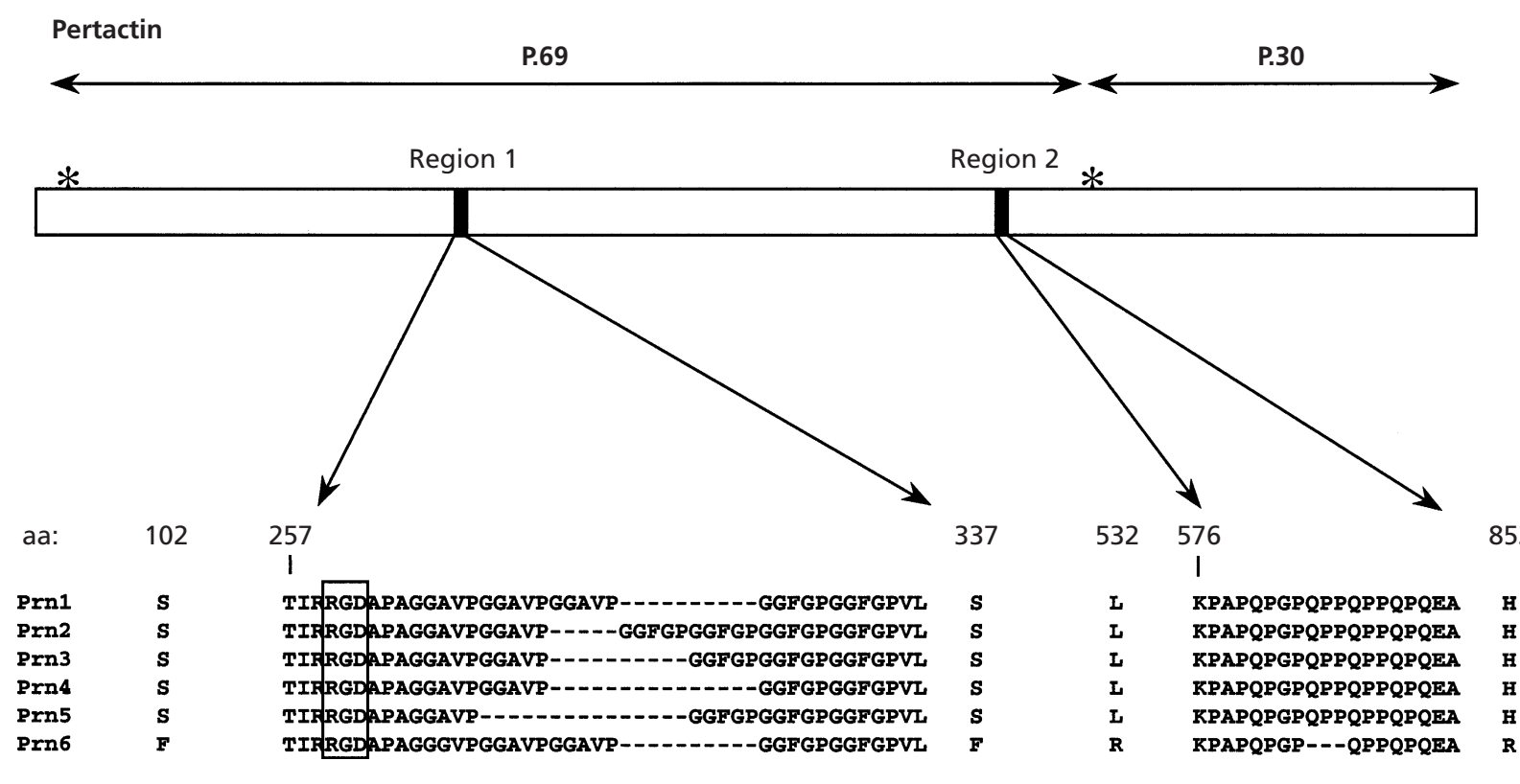

Fig. 1. Structure of the pertactin gene and location of polymorphic sites. The proteolytic cleavage sites are indicated with asterisks and the parts of the gene resulting in the products P.69 and P.30 are indicated. The RGD sequence involved in attachment to host receptors has been boxed. Dashes indicate gaps in the sequence introduced to increase the number of matches. Numbers indicate the position of amino acids in Prn1 relative to the $\mathrm{N}$ terminus of the unprocessed molecule.

proteolytically processed at its $\mathrm{N}$ and $\mathrm{C}$ termini to produce P.69 and P.30 (Fig. 1), which are located at the cell surface and in the outer membrane, respectively (Charles et al., 1994). P.69/pertactin (henceforth designated as pertactin), but not P.30, is included in acellular vaccines. It contains the amino acid triplet arginineglycine-aspartic acid (RGD), a sequence motif which functions as a cell-binding site in a number of mammalian proteins. It has been shown that the pertactin RGD sequence is also involved in adherence to host cells (Leininger et al., 1992).

Polymorphism in pertactin is mainly found in two regions composed of proline-rich repeated sequences, designated regions 1 and 2 (Fig. 1) (Mooi et al., 1998). Most variation is found in region 1 which is located proximally to the $\mathrm{N}$ terminus, flanking the $\mathrm{RGD}$ sequence, and consists of repeats of the Gly-Gly-X-XPro (GGxxP) motif. The crystal structure of pertactin predicts that both the RGD sequence and the GGxxP motif are exposed at the surface of pertactin (Emsley et al., 1996). Region 2 is located more towards the C terminus and is composed of repeats of Pro-Glu-Pro (PQP).

Although epidemiological studies suggest that variation in surface antigens increases the fitness of B. pertussis, in terms of epidemiological spread, in immunized populations no direct evidence has yet been presented for its immunological relevance (Mooi et al., 1998; van Loo et al., 1999). Here we studied the immunological importance of the polymorphism in pertactin. Since variation in pertactin is essentially limited to region 1 , we focused on this domain.

\section{METHODS}

Bacterial strains and plasmids. Bordetella pertussis, Bordetella parapertussis and Bordetella bronchiseptica strains used in this study are indicated in Table 1 . The clinical isolates used for mouse challenge studies were isolated from Dutch patients in the period 1949-1996. Bordetella strains were grown on Bordet-Gengou (BG) agar (Difco Catalogue no. 0048-17-5) supplemented with $1 \%(\mathrm{v} / \mathrm{v})$ glycerol and $15 \%(\mathrm{v} / \mathrm{v})$ sheep blood at $35^{\circ} \mathrm{C}$ for $3 \mathrm{~d}$. Escherichia coli strains DH5 $\alpha$ and BL21(DE3) were used for the propagation of plasmids. E. coli strains were routinely grown in L-broth or on L-agar supplemented with antibiotics. The pMAL-c2 vector was purchased from New England Biolabs.

DNA sequence determination. The pertactin genes of isolates used in this study were sequenced previously or in this study (Mooi et al., 1998, 1999; Mastrantonio et al., 1999; Li et al., 1991) (Table 1). Except for the clinical isolates, the prn genes were sequenced completely on both strands. In the case of the clinical isolates, region 1 was sequenced in all isolates, whereas region 2 was sequenced in $65 \%$ of the isolates. No polymorphism in region 2 was detected. DNA was isolated using standard procedures. DNA sequence determination was performed by direct sequencing of PCR products, using the ABI Prism Dye Terminator Cycle Sequencing Ready Reaction Kit (Perkin Elmer-Applied Biosystems). The products were analysed on a 373 ABI DNA sequencer (Perkin Elmer).

Construction of maltose-binding protein (MBP) containing the pertactin polymorphic region 1. Part of the ORF of the prn1 gene, encoding the amino acid sequence TIRRGDAPAGGAVPGGAVPGGAVPGGFGPGGFGPVL (defined as region 1), was expressed in E. coli as a fusion with the MBP by cloning the corresponding pertactin DNA sequence in the pMAL-c2 vector. The pertactin sequence was obtained by PCR using the primers 5'-CGGGATCCACGATACGGCGCGGGGAC-3' and 5'-GCTCTAGAGAGGACGGGACCGA- 
Table 1. Bordetella strains used in this study

\begin{tabular}{|c|c|c|c|c|c|c|}
\hline Strain & Original designation & Species & Source & prn type & Accession no. & Reference \\
\hline $\mathrm{B} 5^{*}$ & & B. pertussis & USA & prn1 & AJ011091 & Mooi et al. (1998) $\mathbb{S}$ \\
\hline B391† & & B. pertussis & Netherlands & prn1 & AJ011091 & Mooi et al. (1998) \\
\hline B394* & & B. pertussis & Netherlands & $\operatorname{prn} 2$ & AJ011092 & This work $\mathbb{R}$ \\
\hline $\mathrm{B} 596 \%$ & & B. pertussis & Netherlands & prn2 & AJ011092 & This work $\mathbb{S}$ \\
\hline $\mathrm{B} 365 \dagger$ & & B. pertussis & Netherlands & prn3 & AJ011093 & Mooi et al. (1998) $\mathbb{S}$ \\
\hline $\mathrm{B} 647+$ & & B. pertussis & Netherlands & prn3 & AJ011093 & This work $\mathbb{R}$ \\
\hline $\mathrm{B} 705^{*+}+$ & & B. pertussis & Finland & prn4 & AJ011015 & Mooi et al. (1999) \\
\hline B935† & & B. pertussis & Italy & prn5 & AJ011016 & Mastrantonio et al. (1999) \\
\hline B1148: & & B. pertussis & Italy & prn5 & AJ011016 & Mastrantonio et al. (1999)\$ \\
\hline B1120† & 18323 & B. pertussis & USA & prn6 & AJ132095 & This work $\mathbb{S}$ \\
\hline B213‡\# & Tohama & B. pertussis & Japan & prn1 & AJ011091 & This work $\mathbb{S}$ \\
\hline B1296‡ & & B. pertussis & Netherlands & prn2 & AJ011092 & This work $\mathbb{S}$ \\
\hline B1400‡ & & B. pertussis & Netherlands & prn3 & AJ011093 & This work $\mathbb{S}$ \\
\hline B14† & & B. bronchiseptica & & prn & AJ245927 & This work \\
\hline B24† & & B. parapertussis & Netherlands & prn & X54547 & Li et al. (1991)S \\
\hline Clinical isolates $\| \neq$ & & B. pertussis & Netherlands & prn1, prn 2 or prn 3 & & \\
\hline
\end{tabular}

* Used for construction of the MBP fusion proteins.

†Used for immunoblotting.

$\neq$ Used for challenge experiments.

SAccession no. refers to an identical, previously submitted, sequence from another strain.

\| Isolated from Dutch patients in the period 1949-1996.

In the case of the clinical isolates, prn genes were not sequenced completely. Region 1 was sequenced in all strains, whereas region 2 was sequenced in $20 \%$ of the strains. No polymorphism in region 2 was detected.

\# Streptomycin-resistant derivative of Tohama.

AGCC-3' and chromosomal DNA of B. pertussis strain B5 as template. In the primers the $\mathrm{BamHI}$ and $\mathrm{XbaI}$ restriction sites, introduced to facilitate cloning, are underlined, whereas pertactin-derived sequences are indicated in bold type. PCR products derived from prn2, prn3, prn4 and prn5 were obtained in a similar way using the appropriate $B$. pertussis isolates B394, B365, B705 or B1148, respectively (Table 1). Gel-purified PCR products were digested with BamHI and $\mathrm{Xba \textrm {I }}$ and subsequently ligated in $\mathrm{BamHI} / \mathrm{X} b a \mathrm{I}$-digested pMAL-c2. All plasmid constructs were checked by DNA sequencing.

Purification of MBP-pertactin fusion proteins. E. coli BL21(DE3) cultures $(500 \mathrm{ml})$ carrying pMAL-c2 constructs were grown in L-broth medium containing ampicillin $\left(200 \mu \mathrm{g} \mathrm{ml}^{-1}\right)$ and $1 \%(\mathrm{w} / \mathrm{v})$ glucose at $37^{\circ} \mathrm{C}$. At an $\mathrm{OD}_{600}$ of $0 \cdot 5$, expression of the MBP fusion protein was induced by the addition of IPTG to a final concentration of $0.3 \mathrm{mM}$. After induction, growth was allowed to proceed for $2 \mathrm{~h}$ and cells were harvested by centrifugation at $13000 \mathrm{~g}$ for $20 \mathrm{~min}$. The pellet was resuspended in lysis buffer $\left(10 \mathrm{mM} \mathrm{NaPO}_{4}, \mathrm{pH} 7 \cdot 2\right.$, $0.5 \mathrm{M} \mathrm{NaCl}, 0.25 \%$, v/v, Tween 20, $10 \mathrm{mM}$ EDTA and $0.1 \mathrm{mM}$ PMSF) and stored at $-20^{\circ} \mathrm{C}$. After thawing, the cell suspension was sonicated in ice for $4 \times 30 \mathrm{~s}$ with $2 \mathrm{~min}$ intervals (Branson Sonifier 250, normal tip, 50\% output). Extracts were diluted to $100 \mathrm{ml}$ with column buffer A $(20 \mathrm{mM}$ Tris, $200 \mathrm{mM} \mathrm{NaCl}, 1 \mathrm{mM}$ EDTA, $\mathrm{pH} 7 \cdot 4$ ) and applied on a $5 \mathrm{ml}$ amylose column. After extensive washing with buffer A, bound proteins were eluted with buffer A, supplemented with $10 \mathrm{mM}$ maltose and fractions of $1 \mathrm{ml}$ were collected. Purity was $>99 \%$, as estimated by SDS-PAGE followed by Coomassie brilliant blue (Serva) staining.

Production of polyclonal and monoclonal antibodies. Polyclonal antiserum against pertactin was prepared by repeated injection (on day 0 and day 28) of BALB/c mice with $5 \mu \mathrm{g}$ Prn1, kindly provided by Chiron-Biocine, in PBS containing
$0.35 \%(\mathrm{v} / \mathrm{v})$ Alhydrogel. Mice were bled on day 42. mAbs PeM1, PeM2, PeM3, PeM4, PeM5, PeM6 and PeM7 were generated by injection of BALB/c mice subcutaneously three times with purified pertactin mixed with Specol. PeM70, PeM71 and PeM72 were generated similarly using MBP-Prn1 instead of Prn1. For the production of PeM68, mice were injected with MBP-Prn5. PeM80, PeM84 and PeM85 were generated using Prn5. Three days before the fusion, mice were boosted intravenously. Spleens cells were fused with mouse SP2/0 myeloma cells using 50 \% PEG-1500 (Boehringer Mannheim). Hybridomas secreting antibody to pertactin were selected by ELISA and cloned twice by limiting dilution. mAbs were purified by protein-G affinity chromatography (Pharmacia).

Synthesis of peptides. Peptides were assembled by using an automated multiple peptide synthesizer, equipped with a 48-column reaction block (AMS 422; ABIMED AnalysenTechnik) (Brugghe et al., 1994). Peptides used for epitope mapping were $\mathrm{N}$-terminally acetylated multiple (i.e. octameric) antigenic peptides (MAPs) (Tam \& Zavala, 1989), prepared as described previously (Rouppe van der Voort et al., 1997). The amino acid sequences of the pertactin region 1-specific peptides are listed in Table 2a. Peptides used for immunization contained the same amino acid sequence but were monomeric. These peptides were N-terminally elongated with an $S$-acetylmercaptoacetyl group (Drijfhout et al., 1990) and conjugated to tetanus toxoid (Van der Ley et al., 1991; Brugghe et al., 1994). Control peptide-tetanus toxoid conjugates used for immunizations were derived from meningococcal PorA.

Immunoblotting. Cell-free extracts of B. pertussis (isolates B391, B596, B647, B705, B935, B1120, B14 and B24), or purified MBP fusion proteins, were analysed by SDS-PAGE as described by Laemmli (1970). Proteins were transferred to nitrocellulose filters by electroblotting (Biometra semi-dry blotting) using $5 \mathrm{~mA} \mathrm{~cm}^{-2}$ for $30 \mathrm{~min}$. After blocking with 
Table 2. Amino acid sequence of peptides used for epitope-mapping and vaccination

The sequence of each individual peptide is given; the RGD motive, involved in adherence, has been underlined. Binding of mAbs to peptides is indicated by ' + ' (binding) and '-' (no binding). Peptides used for vaccination were conjugated to tetanus toxoid. The meningococcal peptides were used as negative controls in the vaccination experiments.

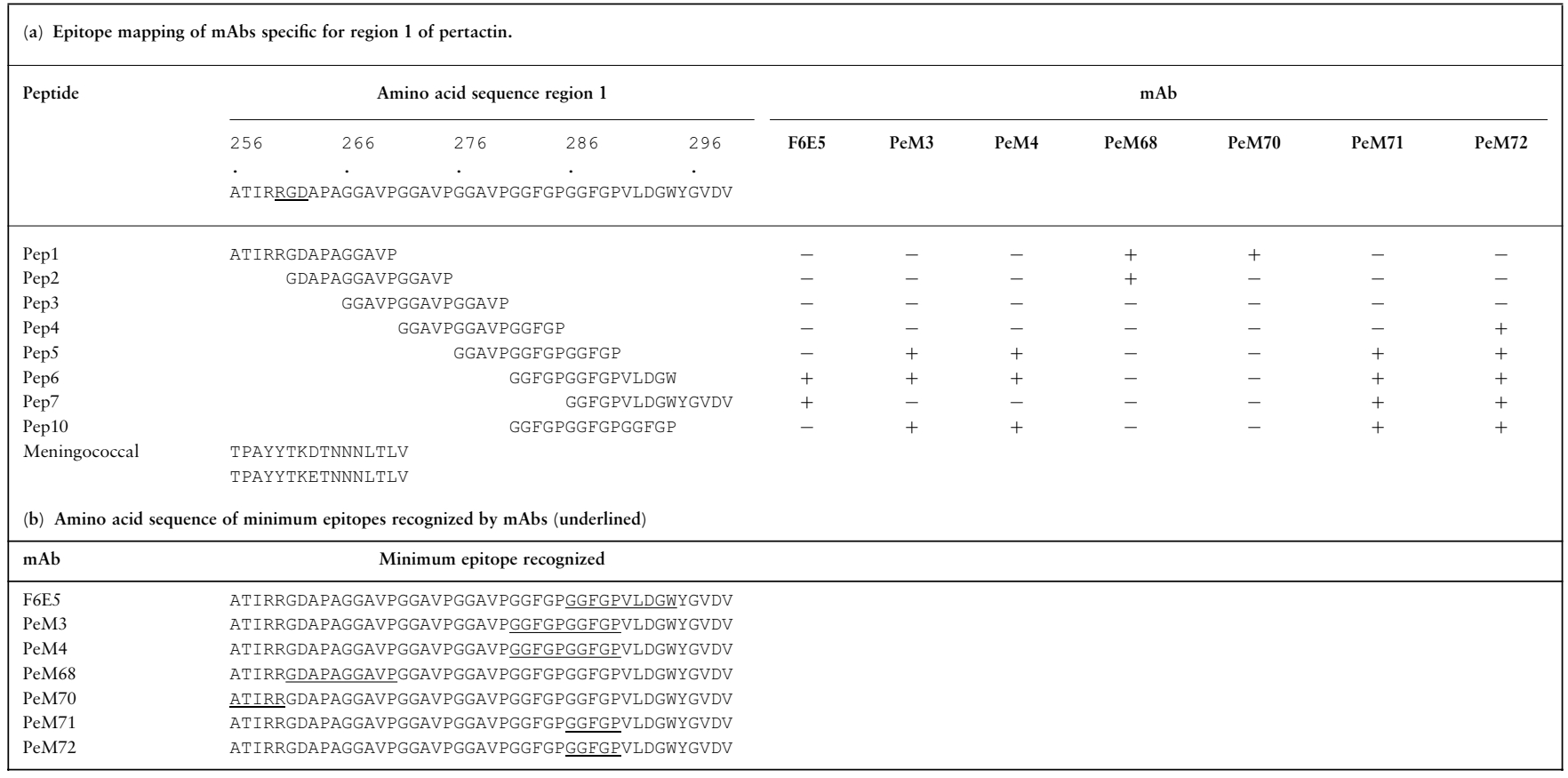

$0 \cdot 5 \%(\mathrm{w} / \mathrm{v})$ Protifar non-fat dry milk, $0 \cdot 1 \%$ BSA (w/v) and $0 \cdot 1 \%(\mathrm{v} / \mathrm{v})$ Tween 20 in PBS, the filters were incubated for $2 \mathrm{~h}$ with antiserum or mAbs. Filters were washed three times for $10 \mathrm{~min}$ in PBS containing $1 \%$ Tween and incubated for $1 \mathrm{~h}$ with goat anti-mouse total IgG conjugated to horseradish peroxidase (HRP) in PBS. After two $10 \mathrm{~min}$ washes in PBS supplemented with $1 \%$ Tween 20 , followed by a 10 min wash in PBS, filters were incubated with the ECL substrate (Amersham Pharmacia Biotech) and bound HRP was visualized by autoradiography.

Epitope mapping. Polystyrene 96-well ELISA plates (Greiner) were coated for $2 \mathrm{~h}$ at $37^{\circ} \mathrm{C}$ with $100 \mu \mathrm{l}$ per well multimeric peptides $\left(2 \mu \mathrm{g} \mathrm{ml}^{-1}\right)$ dissolved in PBS. Plates were washed four times with $200 \mu \mathrm{l}$ PBS supplemented with $0 \cdot 05 \%$ Tween 20 (PBST) per well using the TitretekPlus M96V washer and blocked by incubation with PBST supplemented with $0.5 \%$ (w/v) bovine serum albumin (BSA; Sigma) for $1 \mathrm{~h}$ at room temperature. mAbs (murine), diluted in $0.5 \%$ BSA in PBST were added to the wells and incubated for $2 \mathrm{~h}$ at $37^{\circ} \mathrm{C}$ followed by four washings as described above. Bound antibodies were detected using HRP-conjugated anti-mouse total IgG (Cappel; Organon Technica). Mouse IgG subclasses were determined by using a mouse $\mathrm{mAb}$ isotyping kit (Isostrip; Boehringer). Extinctions $\left(\mathrm{OD}_{450}\right)$ was measured with a BioTek plate reader (EL312e).

Immunization and challenge of mice. $B$. pertussis isolates, all streptomycin-resistant, were grown on BG agar supplemented with streptomycin $\left(30 \mu \mathrm{g} \mathrm{ml}^{-1}\right)$ at $35^{\circ} \mathrm{C}$ for $3 \mathrm{~d}$. Subsequently the bacteria were plated on $\mathrm{BG}$ agar plates without streptomycin. After $3 \mathrm{~d}$, bacteria were harvested and resuspended in Verwey medium (Verwey et al., 1949) to a concentration of $5 \times 10^{8}$ bacteria $\mathrm{ml}^{-1}$. An aliquot of the final suspension was diluted and plated to determine the c.f.u. of the challenge inoculum. Groups of eight female BALB/c mice (RIVM or Harlan; OlaHsd) were used for immunization. For passive immunization, $250 \mu \mathrm{g}$ of a purified $\mathrm{mAb}$ was injected intravenously into 4-week-old mice. Mice were infected $24 \mathrm{~h}$ later. For active immunization with (poly)peptides, 3-week-old mice were immunized subcutaneously on day 0, day 14 and day 28 with $0.5 \mathrm{ml}$ PBS containing $20 \mu \mathrm{g}$ Quil A (Spikoside; Iscotec) and $50 \mu \mathrm{g}$ tetanus-conjugated peptide or $15 \mu \mathrm{g} \operatorname{Prn} 1$. In case of vaccination with the Dutch whole cell vaccine (which contains diphtheria and tetanus toxoids, and inactivated polio, in addition to the pertussis component), mice were immunized twice on day 0 and day 14 with a 1/1000 human dose in PBS with $0.325 \%$ aluminium hydroxide (Alu-Gel-S suspension; Boehringer Ingelheim). When the mix of seven peptides was used, equal amounts of each peptide conjugate (i.e. $6 \cdot 25 \mu \mathrm{g}$ ) were present in the vaccine. Mice were infected $14 \mathrm{~d}$ after the last immunization. For infection, mice were lightly anaesthetized with ether and a drop of $20 \mu$ of the inoculum was placed on top of each nostril and allowed to be inhaled by the animal. Mice were infected with a total amount of $2 \times 10^{7} \mathrm{~B}$. pertussis cells. Three days after infection mice were sacrificed by intraperitoneal injection of an overdose of Nembutal (Sanofi/ Algin) and lungs, trachea and blood were collected. For the determination of bacterial colonization, lungs were homogenized in $900 \mu \mathrm{l}$ Verwey medium (Verwey et al., 1949) for $10 \mathrm{~s}$ at 20000 r.p.m. using a handheld homogenizer (Pro200; Pro Scientific). The trachea was excised and vortexed in $200 \mu \mathrm{l}$ Verwey medium with five glass pearls (diam. $3 \mathrm{~mm}$ ) for $30 \mathrm{~s}$. Appropriate dilutions of the homogenates were plated on BG agar plates supplemented with streptomycin $\left(30 \mu \mathrm{g} \mathrm{ml}^{-1}\right)$. The number of c.f.u. was counted after $4 \mathrm{~d}$ incubation at $35^{\circ} \mathrm{C}$. Levels of serum antibody directed against antigens used for 
vaccination was determined by ELISA as described above. Plates were coated using tetanus toxoid $\left(2 \mu \mathrm{g} \mathrm{ml}^{-1}\right)$ or Prn1 $\left(2 \mu \mathrm{g} \mathrm{ml}^{-1}\right)$. Extinctions were measured with a BioTek plate reader (EL312e) and titres were calculated with Kineticalc (KC4; BioLyse).

Blocking ELISA. Blocking ELISA was performed essentially as described by Berbers et al. (1993). Plates were coated with $\operatorname{Prn} 1\left(2 \mu \mathrm{g} \mathrm{ml}^{-1}\right)$ as described above. After washing and blocking, the wells were incubated with $100 \mu \mathrm{l}$ of serial twofold dilutions of human serum diluted in $0.5 \%(\mathrm{w} / \mathrm{v})$ BSA in PBST for $2 \mathrm{~h}$ at $22^{\circ} \mathrm{C}$. Human sera were from two sources. One serum was from a vaccinated child that was recently infected with pertussis. The serum sample was taken $47 \mathrm{~d}$ after the onset of the disease. The second serum preparation comprised a mix of sera from several recently infected pertussis patients who were fully vaccinated. After washing the plates, a pertactin-specific murine mAb, PeM7, PeM2, PeM5 or PeM6, was added and the plates were incubated for $2 \mathrm{~h}$ at $22{ }^{\circ} \mathrm{C}$. After the plates were washed thoroughly, they were developed and read as described above.

Statistical analyses. $P$-values (two-sided) were calculated by using Student's $t$ test.

\section{RESULTS}

\section{Characterization of mAbs against pertactin}

Previously, we identified six different pertactin types in $B$. pertussis strains circulating in Europe, of which three (Prn1-3) are found in The Netherlands (Mooi et al., 1998). Variation between the pertactin types is mainly limited to region 1 and consists of deletions or insertions of the repeat unit GGxxP (Fig. 1) (Mooi et al., 1998, 1999; Mastrantonio et al., 1999). Here we investigated whether polymorphism in region 1 affected antibody binding, i.e. represented antigenic variation. To this purpose several mAbs were raised, using pertactin variants and MBP fusion proteins with region 1 derived from different pertactin variants.

Binding of the mAbs to the six $B$. pertussis pertactin types and the homologous proteins derived from the closely related species $B$. bronchiseptica and $B$. parapertussis was analysed by immunoblotting. To identify polymorphism in pertactin outside region 1 , the pertactin genes of all isolates used for immunoblotting were sequenced completely. Compared to prn1, the B. bronchiseptica and $B$. parapertussis pertactin genes revealed mutations resulting in amino acid substitutions over the whole length of the encoded protein (not shown). However, within B. pertussis only Prn6 showed polymorphism outside region 1; compared to Prn1, Prn6 contained 4 aa substitutions at positions 102, 337, 532, 853 and a deletion of 3 aa in region 2 (Fig. 1). Of the 14 $\mathrm{mAbs}$ tested, seven cross-reacted with pertactin derived from $B$. bronchiseptica and B. parapertussis (Table 3) and two (PeM5 and PeM7) showed differential binding to $B$. pertussis pertactin (Table 3 ). PeM5 showed highest and lowest binding to Prn1 and Prn6, respectively. Intermediate binding was observed with Prn2-5. PeM7, although raised with $\operatorname{Prn} 1$, showed a much stronger reaction with Prn6 compared to Prn1. Weak binding was observed with Prn2-5 (Table 3). Since, with the exception of Prn6, the different pertactin proteins do not vary outside region 1 , the differential binding of $\mathrm{mAbs}$ is due to recognition of an epitope encompassing region 1 , or an epitope outside region 1 that is affected by changes in region 1 (both of which will be henceforth referred to as a region 1-dependent epitopes). Taken together, these results indicate that variation in region 1 affects antibody binding.

The ability of the mAbs to bind to region 1 was also studied with MBP fusion proteins harbouring region 1 derived from the pertactin variants Prn1-5. Binding was assessed by immunoblotting. Of the $14 \mathrm{mAbs}$ tested, 7 (PeM3, PeM4, PeM68, PeM70, PeM71, PeM72 and F6E5) bound to the fusion proteins and not to MBP (Table 3). No quantitative differences were observed between these seven $\mathrm{mAb}$ with respect to binding to the MBP fusion proteins. The mAbs that did not bind to the MBP fusion proteins may recognize an epitope located outside region 1 . It is also possible that these $\mathrm{mAbs}$ recognize a conformational region 1-dependent epitope, which folds differently in an MBP fusion protein compared to pertactin. In fact this is probably the case with PeM5 and PeM7, which do not bind to the MBP fusion proteins, although the type specificity of these mAbs suggested that they bound to region 1 of pertactin. Thus 4 out of $10 \mathrm{mAbs}$ raised against intact pertactin were directed against a region 1-dependent epitope, indicating that it is immunogenic in mice.

\section{Epitope mapping}

To delineate the epitopes recognized by the mAbs described above, a set of eight overlapping peptides corresponding to region 1 (Pep1-7 and Pep10) was used (Table 2a). The seven mAbs (F6E5, PeM3, PeM4, PeM68, PeM70, PeM71 and PeM72) which bound to the fusion proteins also bound to the peptides (Table $2 \mathrm{a}$ ). The mAb F6E5 was previously reported to bind a pertactin peptide of 128 aa encompassing the RGD and the GGxxP repeat (Charles et al., 1991). Here we show that F6E5 bound to peptides 6 and 7 only, defining the sequence GGFGPVLDGW as its epitope. Based on their differential binding to the peptides, the epitopes of the other mAbs were also delineated and are shown in Table $2 \mathrm{~b}$. The epitopes comprised of GGFGPGGFGP and GGFGP were each recognized by two mAbs, respectively, PeM3 and PeM4, and PeM71 and PeM72. Epitopes for PeM68 and PeM70 were identified as GDAPAGGAVP and ATIRR, respectively. PeM5 and PeM7 did not bind to the peptides, which is consistent with the assumption that they recognize a conformational epitope.

\section{Antibodies against region 1 are induced in humans}

We looked for the presence of region 1-specific antibodies in human sera using a blocking ELISA. In this assay the ability of human antibodies to compete with $\mathrm{mAb}$ PeM7, which binds to a region 1-dependent epitope (see above), for binding to immobilized Prn1 was 
Table 3. Reactivity of mAbs with pertactin variants or MBP-pertactin fusion proteins containing region 1

\begin{tabular}{|c|c|c|c|c|c|c|c|c|c|c|c|c|c|}
\hline \multirow[t]{2}{*}{$\mathrm{mAb}$} & \multirow{2}{*}{$\begin{array}{l}\text { IG sub- } \\
\text { type }\end{array}$} & \multirow{2}{*}{$\begin{array}{l}\text { Antigen used } \\
\text { for } \\
\text { immunization }\end{array}$} & \multicolumn{10}{|c|}{ Antigens used for immunoblotting } & \multirow{2}{*}{$\begin{array}{c}\text { Putative structure } \\
\text { of epitope }\end{array}$} \\
\hline & & & Prn1 & $\operatorname{Prn} 2$ & Prn3 & Prn4 & Prn5 & Prn6 & $\mathrm{Bbr}$ & Bpp & MBP-Prn1-5* & MBP & \\
\hline PeM 1 & $\operatorname{IgG1}$ & Prn1 & + & + & + & + & + & + & + & + & - & - & Not known \\
\hline PeM 2 & IgG1 & Prn1 & + & + & + & + & + & + & + & + & - & - & Not known \\
\hline PeM 3 & $\operatorname{IgG1}$ & Prn1 & + & + & + & + & + & + & - & - & + & - & Linear \\
\hline PeM 4 & $\operatorname{IgG1}$ & Prn1 & + & + & + & + & + & + & - & - & + & - & Linear \\
\hline PeM 5 & IgG1 & Prn1 & ++ & + & + & + & + & \pm & - & - & - & - & Conformational \\
\hline PeM 7 & IgG1 & Prn1 & + & \pm & \pm & \pm & \pm & ++ & - & - & - & - & Conformational \\
\hline PeM 68 & IgG1 & MBP-Prn5 & + & + & + & + & + & + & + & + & + & - & Linear \\
\hline PeM 70 & $\operatorname{IgG} 1$ & MBP-Prn1 & + & + & + & + & + & + & + & \pm & + & - & Linear \\
\hline PeM 71 & $\operatorname{IgG} 2 \mathrm{a}$ & MBP-Prn1 & + & + & + & + & + & \pm & + & \pm & + & - & Linear \\
\hline PeM 72 & $\operatorname{IgG} 2 \mathrm{a}$ & MBP-Prn1 & + & + & + & + & + & + & + & + & + & - & Linear \\
\hline PeM 80 & IgG1 & Prn5 & + & + & + & + & + & + & - & - & - & - & Not known \\
\hline PeM 84 & IgG1 & $\operatorname{Prn} 5$ & + & + & + & + & + & + & + & + & - & - & Not known \\
\hline PeM 85 & IgG1 & Prn5 & + & + & + & + & + & + & - & - & - & - & Not known \\
\hline F6E5 & $\operatorname{IgG} 1$ & WCV & + & + & + & + & + & + & - & - & + & - & Linear \\
\hline
\end{tabular}

*Identical results were obtained with MBP-Prn1 to MBP-Prn5.

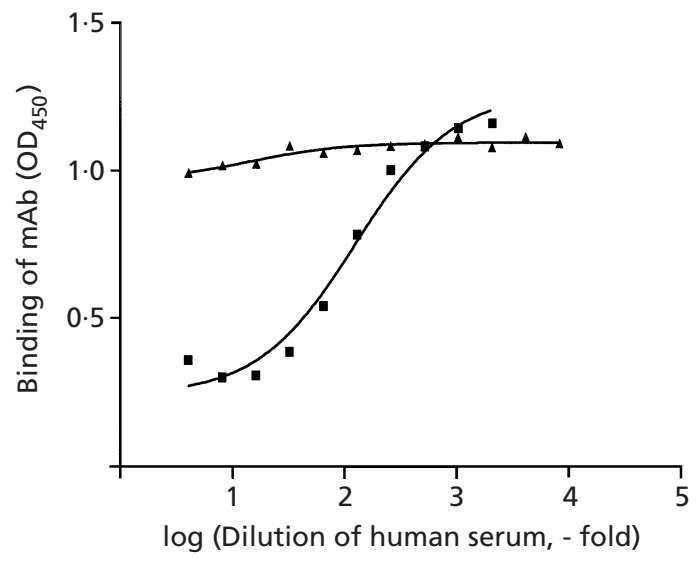

Fig. 2. Sera from pertussis patients harbour antibodies directed against region 1. ELISA plates were coated with Prn1. Binding of mAbs PeM7 ( $\boldsymbol{\square}$; directed against region 1$)$ or PeM2 ( $\boldsymbol{A}$; directed against an epitope present in all pertactin variants) was allowed after pre-incubation with twofold dilutions of human serum. Human serum was from one pertussis patient; similar results were obtained with a pool of sera from different pertussis patients.

assessed. The serum sample was from a child recently infected with B. pertussis. Similar results were obtained with pooled sera derived from several children (not shown). Binding of PeM7 to Prn1 was inhibited in a dose-dependent manner (Fig. 2), indicating the presence of human antibodies directed to the region 1-dependent epitope recognized by PeM7. Binding of PeM2, which recognizes an epitope present in all tested pertactin variants (Table 3), was not inhibited by human antibodies (Fig. 2). The mAb PeM5, which is similar to

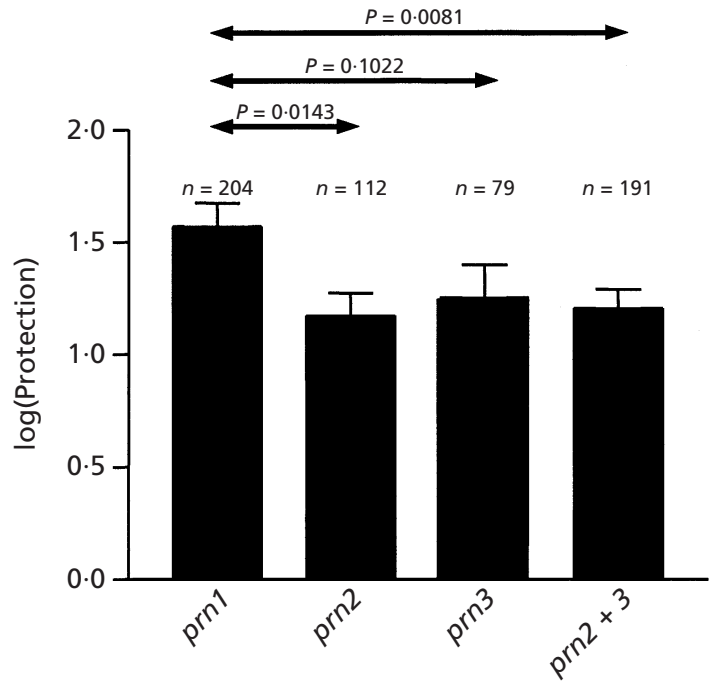

Fig. 3. Efficacy of the Dutch WCV against isolates expressing Prn1, Prn2 or Prn3. Groups of eight mice were immunized with PBS or the Dutch WCV. Both the control groups and vaccinated groups were infected intranasally with different B. pertussis isolates expressing either Prn1, Prn2 or Prn3. In total 23 isolates with Prn1, 14 isolates with Prn2 and 10 isolates with Prn3 were tested in several independent experiments (some isolates were tested more than once). Colonization was measured in the lungs. log(Protection) values were calculated using the following equation: $\log$ (protection) $=\log$ (mean c.f.u. of nonimmunized mice)-log(c.f.u. of each individual immunized mouse). The bars show the mean values; error bars indicate the SEM. $P$ values are indicated.

PeM7 in that it bound to a region 1-dependent epitope (see above), also competed with human antibodies (not shown). Interestingly, mAbs that recognized linear 

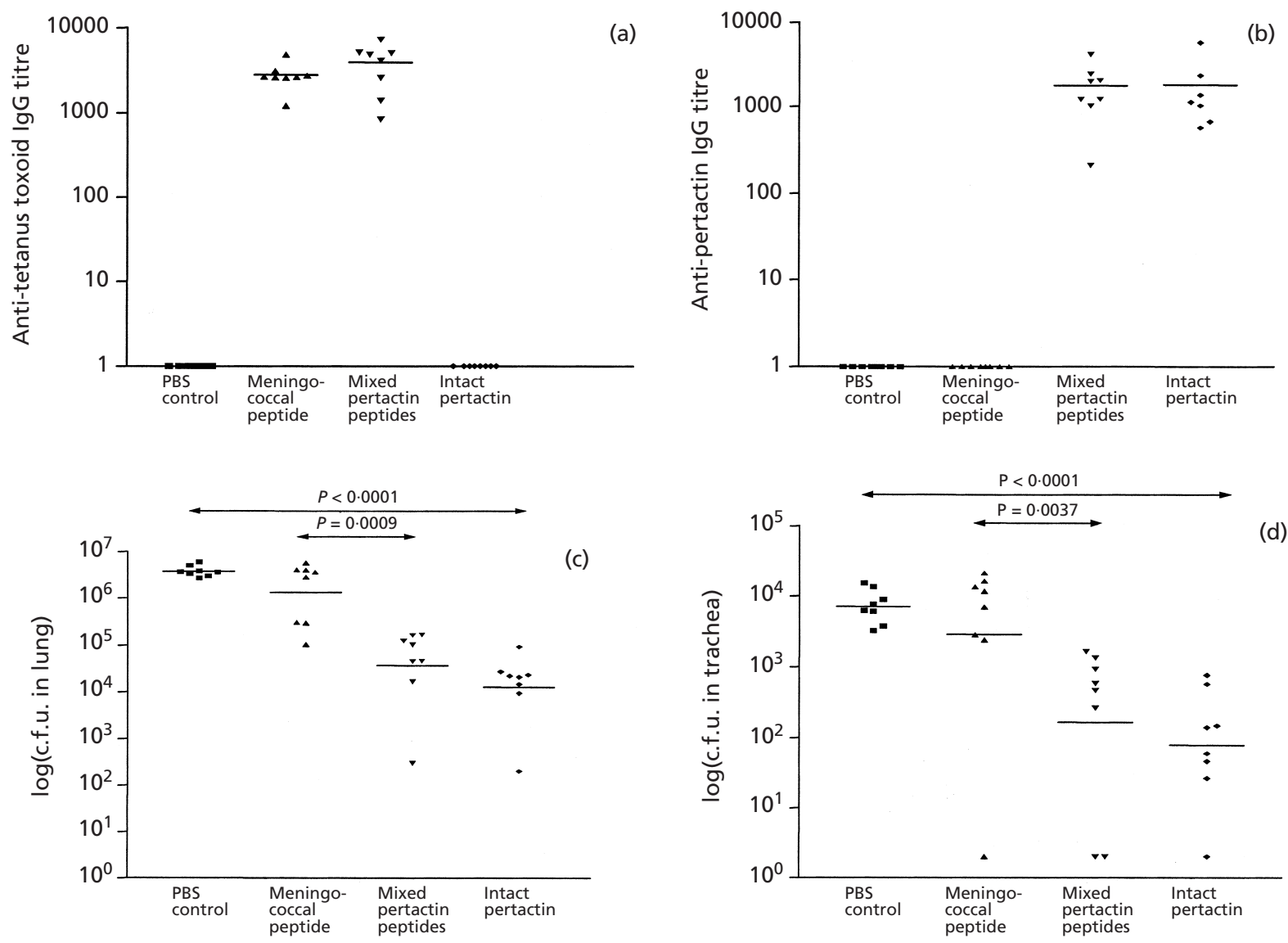

Fig. 4. Protection against intranasal $B$. pertussis infection by immunization with peptides derived from pertactin region 1. Mice were immunized with PBS, a meningococcal peptide, a mixture of peptides derived from region 1 (Pep1-7; Table 2a) or with pertactin (Prn1). Peptides were conjugated to tetanus toxoid. After immunization, mice were intranasally infected with B. pertussis strain B213 expressing Prn1. The amount of bacteria in the lungs and trachea, and antibody titres were determined $3 \mathrm{~d}$ post-infection. (a) Anti-tetanus toxoid IgG titres; (b) anti-Prn1 IgG titres; (c) c.f.u. in the lungs; (d) c.f.u. in trachea. The thin line indicates the mean. $P$ values are indicated. The experiment was performed three times and a representative result is shown.

epitopes in region 1 (e.g. PeM4 and F6E5) were not able to compete with human serum for binding to pertactin (not shown). These results indicate that, in its native state, region 1 elicits antibodies in humans.

\section{Variation in region 1 affects the efficacy of the Dutch WCV in the mouse model}

To determine if variation in pertactin affected vaccine efficacy, mice were immunized with the Dutch WCV and challenged with $B$. pertussis isolates expressing Prn1, Prn2 or Prn3, the predominant types found in most countries (Mooi et al., 1998, 1999; Mastrantonio et al., 1999). Control mice were immunized with PBS. To correct for the different colonizing abilities of isolates in mice, $\log$ (protection) values were calculated (see legend to Fig. 3). We found the Dutch WCV protected against isolates with Prn1 significantly better compared to those carrying non-vaccine-type pertactins $(P=0 \cdot 0081)$ (Fig. $3)$. When the Prn2 and Prn3 isolates were analysed separately, the WCV was also found to be less effective; however, significance was only attained with the Prn2 group $(P=0 \cdot 0143)$.

\section{Region 1 harbours a protective epitope}

To confirm that region 1 was able to induce a protective immune response, mice were immunized with a mixture of seven overlapping peptides derived from region 1 (Pep1-7; Table 2a). Mice in the control group were immunized with a meningococcal peptide (Table $2 a$ ) or with PBS. Immunization with Prn1 served as a positive control. Peptides were conjugated to tetanus toxoid. Analysis of the serum samples of immunized and infected mice revealed that high antibody titres to tetanus toxoid were observed in both groups immunized with the peptides (Fig. 4a), while only mice immunized with the pertactin peptides or with the intact pertactin had anti-pertactin titres (Fig. 4b). Immunization with pertactin peptides reduced colonization in the lungs and trachea 35- and 16-fold, respectively, compared to mice immunized with the meningococcal peptide $(P=0.0009$ 


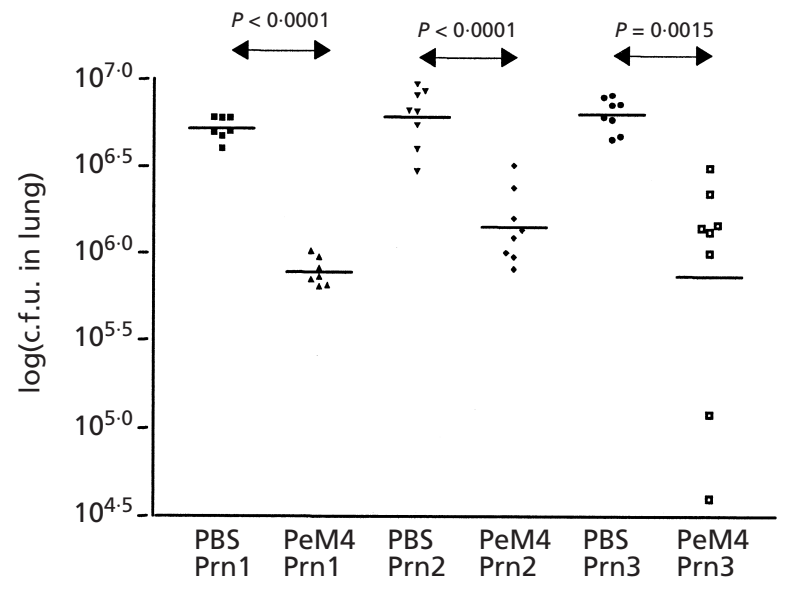

Fig. 5. Passive protection against $B$. pertussis infection by an mAb directed against a linear region 1 epitope of pertactin. Mice were immunized passively by intravenous injection of PeM4 or PBS. After immunization, mice were intranasally infected with B. pertussis B213 (Prn1), B1296 (Prn2) or B1400 (Prn3). The amount of bacteria in the lungs and trachea was determined $3 \mathrm{~d}$ post-infection. The thin line indicates the mean. $P$ values are indicated. The experiment was performed three times and a representative result is shown.

and 0.0037, respectively) (Fig. 4). Immunization with intact pertactin resulted in a significant reduction of colonization in lungs and trachea $(P<0 \cdot 0001)$. In conclusion, both in the trachea and lungs, peptides derived from region 1 were able to induce protective immunity.

The role of region 1 in conferring immunity was confirmed by passive immunization with mAb PeM4. PeM4, which binds to the GGFGPGGFGP sequence in region 1 (see above), was administered intravenously $24 \mathrm{~h}$ prior to challenge. Control mice were injected with PBS. Mice injected with PeM4 showed over 10-fold less colonization of the lungs by $B$. pertussis, compared to mice injected with PBS $(P<0.0001)$ (Fig. 5). In the trachea the reduction in colonization by PeM4 was less pronounced, in some experiments an approximately twofold drop in colonization was seen, whereas in others no significant drop in colonization was observed (not shown).

\section{Cross-immunity can be conferred by a linear epitope from region 1}

The sequence recognized by PeM4 was present in all six pertactin variants, suggesting that cross-immunity could be induced. To test this assumption, mice were immunized passively with PeM4 and subsequently challenged with a $B$. pertussis isolate expressing Prn2 or Prn3 (Fig. $5)$. Mice in the control group were given PBS. As was observed with the isolate expressing Prn1, PeM4 significantly reduced colonization $(P \leqslant 0 \cdot 0015)$ in the lungs of the isolates expressing $\operatorname{Prn} 2$ or Prn3. Importantly, no significant differences were observed between the Prn groups with respect to the degree of immunity conferred by PeM4 in the lungs, indicating cross-immunity. As with Prn1, variable results were obtained in the trachea (not shown). The mixture of seven overlapping peptides derived from region 1 was also found to confer crossimmunity (results not shown). The results obtained with passive and active immunization indicate that region 1 contains a cross-protecting linear epitope that protects equally against isolates expressing distinct pertactin variants.

\section{DISCUSSION}

Studies in animals and humans have indicated that pertactin plays an important role in immunity to pertussis (Novotny et al., 1991; Cherry et al., 1998; Shahin et al., 1990; Storsaeter et al., 1998). Especially relevant are the results of two independent field trials, which revealed a correlation between pertactin antibodies and clinical protection (Cherry \& Olin 1999; Cherry et al., 1998; Storsaeter et al., 1998). Our previous studies have provided indirect epidemiological evidence that variation in pertactin is immunologically relevant and may be linked to the re-emergence of pertussis in vaccinated populations (de Melker et al., 1997; Mooi et al., 1998, 1999; Mastrantonio et al., 1999). For example, isolates with vaccine-type pertactin were found in lower frequencies in vaccinated children compared to nonvaccinated children, suggesting that variation in pertactin affects vaccine efficacy (Mooi et al., 1998). Further, temporal trends in the frequencies of the pertactin and pertussis toxin variants indicated a divergence between vaccine strains and clinical isolates (Mooi et al., 1998, 1999). Here we extend our studies on the immunological relevance of the variable region 1 of pertactin.

We observed that a significant number of the mice mAbs were directed against a region 1-dependent epitope after immunization with pertactin, indicating that this region is immunogenic. Moreover, also in serum from humans recently infected with $B$. pertussis, we detected antibodies against region 1 . Interestingly, $\mathrm{mAbs}$ that recognized a conformational region 1-dependent epitope (Fig. 2), but not those that bound to a linear epitope (not shown), were found to compete with the human antibodies. The reason for this difference is not clear, but it is conceivable that antibodies directed against conformational epitopes bind with higher avidity than antibodies against linear epitopes. It is also possible that infection or vaccination mainly results in the induction of antibodies directed against conformational epitopes of pertactin. In this context it is significant that mAbs directed against conformational region 1-dependent epitopes were type-specific, whereas those that recognized a linear region 1 epitope bound to all $B$. pertussis pertactin variants. Thus, to prevent cross-immunity, the bacteria may have evolved mechanisms to direct the immune response towards conformational epitopes. These data show that region 1 is exposed and able to elicit antibodies both in mice and humans. This is consistent with functional studies, which have implicated this region in adherence (Everest et al., 1996) and 
crystallographic data which indicate that region 1 is exposed as a loop (Emsley et al., 1996). The fact that the binding of two mAbs to Prn was affected by variation in region 1 , indicated that polymorphism in region 1 represented antigenic variation.

A number of linear epitopes recognized by mAbs were mapped within region 1 . One of these mAbs (F6E5) was previously shown to inhibit invasion of HeLa cells by $B$. pertussis and its binding site was mapped to a region of 128 aa residues overlapping the RGD site (Leininger et al., 1992). We defined the F6E5 epitope more precisely with synthetic peptides and located it in the GGxxP repeat region, 23 aa removed from the RGD motif. The inhibitory effect of this $\mathrm{mAb}$ on invasion (Leininger et al., 1991) underlines the importance of antigenic variation in region 1 for bacterial fitness.

Immunization of mice with peptides derived from region 1 significantly reduced colonization of both trachea and lungs, demonstrating the importance of this region for immunity. Further evidence for the importance of region 1 in protective immunity was revealed by the observation that an $\mathrm{mAb}$ (PeM4) directed against a linear epitope in region 1, comprising two GGFGP repeats, was able to confer passive protection in the lungs. The efficacy of this $\mathrm{mAb}$ was much lower in the trachea, however. Protection probably requires transudation of antibodies from the blood to the site of infection (i.e. the mucosal surfaces). It is conceivable that the $\mathrm{mAb}$ used was inefficiently transudated to the trachea. It is not clear on what mechanism the protection by the $\mathrm{mAb}$ is based. Effector functions, such as opsonization and complement activation, may be involved. The isotype of antibody used, IgG1, shows relatively weak effector functions in mice (Ravetch \& Clynes, 1998). Alternatively, the mAbs may block the function of pertactin or hinder colonization by agglutinating bacteria. It should be noted that a function for pertactin in the mouse model has yet to be established: a pertactin-defective mutant was not affected in its ability to colonize the trachea or lungs of mice (Roberts et al., 1991).

A second protective epitope has been located in the PQP repeat region, designated region 2 , which is located in the C-terminal part of pertactin (Fig. 1) (Charles et al., 1991). Like the GGxxP repeat, region 2 was found to be immunogenic in mice (Charles et al., 1991). However, the PQP region is less variable than the GGxxP region and of the hundreds of isolates analysed, only two polymorphisms were observed in the PQP region (Fig. 1). To date, this minor variant, represented by Prn6, was found in two isolates only. Thus the vast majority of isolates analysed do not show variation in the PQP region, suggesting that it plays a less important role in escaping immunity compared to region 1.

Studies using the mouse model indicated that the Dutch WCV was less effective against Prn2 and Prn3 isolates compared to those expressing Prn1 (Fig. 3). Prn1 is produced by the vaccine strains and has been replaced by Prn 2 and Prn 3 in The Netherlands. Prn 2 and Prn3 have also been found to dominate in other countries where the WCV contains Prn1 (Mooi et al., 1999, van Loo et al., 1999). It should be noted that we used clinical isolates which may differ in other properties relevant for immunity than pertactin. However, sequencing of 10 surface-associated proteins revealed that variation was mainly restricted to pertactin (unpublished data). The results obtained in the mouse model are consistent with data obtained from human populations, which indicate that Prn 2 and Prn 3 are less affected by the current WCVs compared to Prn1. The relevance of the mouse as a model for studying pertussis immunity in human models is further substantiated by two independent studies which showed that the results obtained with the intranasal mouse model are congruent with results from humans trials (Mills et al., 1998; Guiso et al., 1999). Boursaux-Eude et al. (1999) used the mouse model to compare the efficacy of acellular vaccines against isolates producing different pertactin and pertussis toxin variants. They concluded that a tri-component vaccine was highly effective in promoting lung clearance of all isolates expressing different pertussis toxin and pertactin variants. The data obtained with different isolates were not compared on a statistical basis, however. Furthermore, in the study of Boursaux-Eude et al. (1999) a much higher vaccine dose was used compared to our study (1/4 and $1 / 1000$ human dose, respectively). In this context it should be noted that we found no significant differences in protection against isolates with different Prn variants when mice were immunized with a relatively high dose of Prn1 (1/10 human dose) (not shown). Nevertheless, the study of Boursaux-Eude et al. (1999) may indicate that acellular vaccines are less affected by antigenic variation than the whole-cell vaccine tested by us.

An $\mathrm{mAb}$ recognizing a linear epitope found in all Prn variants was equally effective against strains with Prn1, $\operatorname{Prn} 2$ and $\operatorname{Prn} 3$ when administered intravenously to mice. Furthermore, a similar observation was made when mice were vaccinated with a mixture of peptides harbouring sequences found in all Prn variants. We hypothesize that linear epitopes derived from region 1 may confer cross-immunity, while conformational epitopes do not. Infection and vaccination may induce mainly antibodies against conformational epitopes.

From the data described in this paper we can conclude that the polymorphic region 1 of pertactin is recognized by the immune system of both mice and humans, that variation in this region affects antibody binding and that this region harbours a protective epitope. Mice experiments suggested that variation in region 1 affects the efficacy of the Dutch WCV. Our results support the assumption that the expansion of isolates which carry non-vaccine type pertactin molecules has contributed to the re-emergence of pertussis in vaccinated populations (Mooi et al., 1998). An important, unresolved, question is whether, and to what extent, variation in pertactin affects the efficacy of acellular vaccines. In addition to pertactin, acellular vaccines contain filamentous haemagglutinin, fimbriae and pertussis toxin, which are also involved in protection against pertussis. Possibly, 
the presence of high concentrations of multiple antigens may minimize the effect of variation in pertactin.

\section{ACKNOWLEDGEMENTS}

We are grateful to Henk Gielen and Hans van Kooten for performing mice experiments. mAbs F6E5 and E4D7 were a generous gift from Dr M. Brennan. This work was supported financially by Praeventiefonds grant 28-2852, The Netherlands.

\section{REFERENCES}

Andrews, R., Herceg, A. \& Roberts, C. (1997). Pertussis notifications in Australia, 1991 to 1997. Commun Dis Intell 21, 145-148.

Bass, J. W. \& Stephenson, S. R. (1987). The return of pertussis. Pediatr Infect Dis J 6, 141-144.

Bass, J. W. \& Wittler, R. R. (1994). Return of epidemic pertussis in the United States. Pediatr Infect Dis J 13, 343-345.

Berbers, G. A. M., Marzec, A. H. J. O., Bastmeijer, M., Gageldonk, P. M. \& Plantinga, A. D. (1993). Blocking ELISA for detection of mumps virus antibodies in human sera. J Virol Methods 42, 155-168.

Boursaux-Eude, C., Thiberge, S., Carletti, G. \& Guiso, N. (1999). Intranasal murine model of Bordetella pertussis infection: II. Sequence variation and protection induced by a tricomponent acellular vaccine. Vaccine 17, 2651-2660.

Brugghe, H. F., Timmermans, H. A. M., Van Unen, L. M. A., Ten Hove, G. J., Van de Werken, G., Poolman, J. T. \& Hoogerhout, P. (1994). Simultaneous multiple synthesis and selective conjugation of cyclized peptides, derived from a surface-loop of a meningococcal class I outer membrane protein. Int J Pept Protein Res 43, 166-172.

Charles, I. G., Li, J. L., Roberts, M. \& 13 other authors (1991). Identification and characterization of a protective immunodominant B cell epitope of pertactin (P.69) from Bordetella pertussis. Eur J Immunol 21, 1147-1153.

Charles, I., Fairweather, N., Pickard, D., Beesley, J., Anderson, R., Dougan, G. \& Roberts, M. (1994). Expression of the Bordetella pertussis P.69 pertactin adhesin in Escherichia coli: fate of the carboxy-terminal domain. Microbiology 140, 3301-3308.

Cherry, J. D. \& Olin, P. D. (1999). The sciences and fiction of pertussis vaccines. Pediatrics 104, 1381-1384.

Cherry, J. D., Gornbein, J., Heininger, U. \& Stehr, K. (1998). A search for serologic correlates of immunity to Bordetella pertussis cough illnesses. Vaccine 16, 1901-1906.

DeSerres, G., Boulianne, N., Douville-Fradet, M. \& Duval, B. (1995). Pertussis in Quebec: ongoing epidemic since the late 1980s. Can Commun Dis Rep 15, 45-48.

Drijfhout, J. W., Bloemhoff, W., Poolman, J. T. \& Hoogerhout, P. (1990). Solid-phase synthesis and applications of $N$-(S-acetylmercaptoacetyl) peptides. Anal Biochem 187, 349-354.

Emsley, P., Charles, I. G., Fairweather, N. F. \& Isaacs, N. W. (1996). Structure of Bordetella pertussis virulence factor P.69 pertactin. Nature 381, 90-92.

Everest, P., Li, J. L., Douce, G., Charles, I., Deazavedo, J., Chatfield, S., Dougan, G. \& Roberts, M. (1996). Role of the Bordetella pertussis P.69/pertactin protein and the P.69/pertactin RGD motif in the adherence to and invasion of mammalian cells. Microbiology 142, 3261-3268.

Guiso, N., Capiau, C., Carletti, G., Poolman, J. \& Hauser, P. (1999). Intranasal murine model of Bordetella pertussis infection. I.
Prediction of protection in human infants by acellular vaccines. Vaccine 17, 2366-2376.

Henderson, I. R., Navarro-Garcia, F. \& Nataro, J. P. (1998). The great escape: structure and function of the autotransporter proteins. Trends Microbiol 6, 370-378.

Hewlett, E. L. (1997). Pertussis: current concepts of pathogenesis and prevention. Pediatr Infect Dis J 16, S78-S84.

Kimura, A., Mountzouros, K. T., Relman, D. A., Falkow, S. \& Cowell, J. L. (1990). Bordetella pertussis filamentous hemagglutinin: evaluation as a protective antigen and colonization factor in a mouse respiratory infection model. Infect Immun 58, 7-16.

Laemmli, U. K. (1970). Cleavage of structural proteins during the assembly of the head of bacteriophage T4. Nature 227, 680-685.

Leininger, E., Roberts, M., Kenimer, J. G., Charles, I. G., Fairweather, N., Novotny, P. \& Brennan, M. J. (1991). Pertactin, an Arg Gly Asp containing Bordetella pertussis surface protein that promotes adherence of mammalian cells. Proc Natl Acad Sci U S A 88, 345-349.

Leininger, E., Ewanowich, C. A., Bhargava, A., Peppler, M. S., Kenimer, J. G. \& Brennan, M. J. (1992). Comparative roles of the Arg Gly Asp sequence present in the Bordetella pertussis adhesins pertactin and filamentous hemagglutinin. Infect Immun 60, 2380-2385.

Li, L. J., Dougan, G., Novotny, P. \& Charles, I. G. (1991). P.70 pertactin, an outer-membrane protein from Bordetella parapertussis: cloning, nucleotide sequence and surface expression in Escherichia coli. Mol Microbiol 5, 409-417.

van Loo, I. H., Van der Heide, H. G., Nagelkerke, N. J., Verhoef, J. \& Mooi, F. R. (1999). Temporal trends in the population structure of Bordetella pertussis during 1949-1996 in a highly vaccinated population. J Infect Dis 179, 915-923.

Mastrantonio, P., Spigaglia, P., Van Oirschot, H., Van der Heide, H., Heuvelman, K., Stefanelli, P. \& Mooi, F. R. (1999). Antigenic variants in Bordetella pertussis strains isolated from vaccinated and unvaccinated children. Microbiology 145, 2069-2075.

de Melker, H. E., Conyn-van Spaendonck, M. A., Rumke, H. C., van Wijngaarden, J. K., Mooi, F. R. \& Schellekens, J. F. (1997). Pertussis in The Netherlands: an outbreak despite high levels of immunization with whole-cell vaccine. Emerg Infect Dis 3, 175-178.

Mills, K. H., Ryan, M., Ryan, E. \& Mahon, B. P. (1998). A murine model in which protection correlates with pertussis vaccine efficacy in children reveals complementary roles for humoral and cell-mediated immunity in protection against Bordetella pertussis. Infect Immun 66, 594-602.

Mooi, F. R., Van Oirschot, H., Heuvelman, K., Van der Heide, H. G. J., Gaastra, W. \& Willems, R. J. L. (1998). Polymorphism in the Bordetella pertussis virulence factors P.69/Pertactin and pertussis toxin in the Netherlands: temporal trends and evidence for vaccine-driven evolution. Infect Immun 66, 670-675.

Mooi, F. R., He, Q., Van Oirschot, H. \& Mertsola, J. (1999). Variation in Bordetella pertussis virulence factors pertussis toxin and pertactin in vaccine strains and clinical isolates in Finland. Infect Immun 67, 3133-3134.

Novotny, P., Chubb, A. P., Cownley, K. \& Charles, I. G. (1991). Biologic and protective properties of the $69 \mathrm{kDA}$ outer membrane protein of Bordetella pertussis: a novel formulation for an acellular pertussis vaccine. J Infect Dis 164, 114-122.

Plotkin, S. A. \& Cadoz, M. (1997). Acellular vaccine efficacy trials. Pediatr Infect Dis J 16, 913-914.

Ravetch, J. V. \& Clynes, R. A. (1998). Divergent roles for Fc 
receptors and complement in vivo. Annu Rev Immunol 16, 421-432.

Roberts, M., Fairweather, N. F., Leininger, E., Pickard, D., Hewlett, E. L., Robinson, A., Hayward, C., Dougan, G. \& Charles, I. G. (1991). Construction and characterization of Bordetella pertussis mutants lacking the vir regulated P.69 outer membrane protein. Mol Microbiol 5, 1393-1404.

Robinson, A., Ashworth, L. A., Baskerville, A. \& Irons, L. I. (1985). Protection against intranasal infection of mice with Bordetella pertussis. Dev Biol Stand 61, 165-172.

Rouppe van der Voort, E. M., Kuipers, B., Brugghe, H. F., Van Unen, L. M., Timmermans, H. A., Hoogerhout, P. \& Poolman, J. T. (1997). Epitope specificity of murine and human bactericidal antibodies against PorA P1.7,16 induced with experimental meningococcal group B vaccines. FEMS Immunol Med Microbiol 17, 139-148.

Sato, H. \& Sato, Y. (1984). Bordetella pertussis infection in mice: correlation of specific antibodies against two antigens, pertussis toxin, and filamentous hemagglutinin with mouse protection in an intracerebral or aerosol challenge system. Infect Immun 46, 415-421.

Shahin, R. D., Brennan, M. J., Li, Z. M., Meade, B. D. \& Manclark, C. R. (1990). Characterization of the protective capacity and immunogenicity of the $69 \mathrm{kD}$ outer membrane protein of Bordetella pertussis. J Exp Med 171, 63-73.

Storsaeter, J., Hallander, H. O., Gustafsson, L. \& Olin, P. (1998). Levels of anti-pertussis antibodies related to protection after household exposure to Bordetella pertussis. Vaccine 16, 19071916.

Tam, J. \& Zavala, F. (1989). Multiple Antigen Peptide. A novel approach to increase detection sensitivity of synthetic peptides in solid-phase immunoassays. J Immunol Methods 124, 53-61.

Van der Ley, P., Heckels, J. E., Virji, M., Hoogerhout, P. \& Poolman, T. (1991). Topology of outer membrane porins in Neisseria spp. Infect Immun 59, 2963-2971.

Verwey, W. F., Thiele, E. H., Sage, D. N. \& Schuckhardt, L. T. (1949). A simplified liquid culture medium for the growth of Haemophilus pertussis. J Bacteriol 50, 127-134.

Willems, R. J. L. \& Mooi, F. R. (1996). From whole cell to acellular pertussis vaccines. Rev Med Microbiol 7, 13-21.

Zhang, J. M., Cowell, J. L., Steven, A. C. \& Manclark, C. R. (1985). Purification of serotype 2 fimbriae of Bordetella pertussis and their identification as a mouse protective antigen. Dev Biol Stand 61, 173-185.

Received 10 April 2001; revised 13 July 2001; accepted 1 August 2001. 